\title{
CXXX. THE DETERMINATION OF BLOOD-SUGAR.
}

\section{THE EFFECT OF DIFFERENT DEPROTEINISING AGENTS UPON THE ESTIMATION OF BLOOD-SUGAR.}

\author{
By SIDNEY LIONEL TOMPSETT. \\ From the Biochemical Laboratory of the Institute of Pathology of the \\ Royal Infirmary and University of Glasgow.
}

(Received July 1st, 1930.)

WITHIN recent years many modifications of the earlier methods and many new methods for the determination of blood-sugar have appeared.

De Wesselow [1919] found that the Lewis-Benedict picric acid method [1915] gave 30-50 \% higher results than MacLean's method [1916]. Folin and $\mathrm{Wu}$ [1919] state that their method gives lower results than the LewisBenedict method. Höst and Hatlehol [1920], comparing four methods over a wide range, came to the conclusion that Bang's method [1918] and the Hagedorn and Jensen method [1918] compared fairly well, while that of Folin and $\mathrm{Wu}$ [1919] compared well with Bailey and Myers's [1916] modification of the Lewis-Benedict method. The two former gave somewhat lower results than the two latter. More recently Folin [1926] and Benedict [1927] have evolved methods by which they claim to obtain lower results than with that of Folin and Wu, but Everett [1929] has criticised Benedict's method.

Herbert and Groen [1929] found that they obtained much higher results by the Hagedorn and Jensen method when tungstic acid filtrates and not zinc filtrates were used. They also found that MacLean's method gave higher results with tungstic acid filtrates than with ferric hydroxide filtrates.

Bierry and Moquet [1924] and Harned [1925] employed mercury salts to deproteinise blood with the intention of removing substances other than glucose which were found to reduce the copper reagents used by them. These authors used the Folin and $\mathrm{Wu}$ alkaline copper reagent [1919] for determining the sugar in their filtrates and they claim to have obtained lower results than by the use of tungstic acid filtrates. West, Scharles and Petersen [1929] used mercury salts for deproteinisation in conjunction with a modification of the Shaffer-Hartmann reagent by Somogyi. They also state that they have obtained lower values with mercury filtrates than with tungstic acid filtrates and claim that the difference between the reducing values of the mercury and tungstic acid filtrates was equal to the non-fermentable reducing values 
of the tungstic acid filtrates. Somogyi [1929, 1930] employed zinc sulphate and sodium hydroxide in the cold for preparing filtrates and claimed to obtain thereby filtrates free from uric acid, ergothioneine, glutathione and other nonfermentable reducing substances.

Stepp [1921] found that if phosphotungstic acid filtrates of blood were treated with basic lead acetate, a portion of the reducing substances was precipitated. He considered that these substances were of aldehydic nature. $\mathrm{He}$ found that the reducing values of solutions of pure glucose were unaffected by this treatment.

\section{Determination of the sugar content of tungstic acid filtrates by the method recommended in Part I. (This Journal, p. 1161.)}

All filtrates were prepared according to the technique of Folin and $\mathrm{Wu}$ [1919] and for accuracy $10 \mathrm{cc}$. of filtrate were used in the determinations.

As a preliminary, known quantities of pure glucose were added to determine if these could be estimated quantitatively (Table I).

Table I.

\begin{tabular}{|c|c|c|c|}
\hline $\begin{array}{l}\text { Sugar content } \\
\text { of blood } \\
\text { (mg. per } 100 \mathrm{cc} \text { ) }\end{array}$ & $\begin{array}{c}\text { Glucose } \\
\text { added } \\
\text { (mg. per } 100 \mathrm{cc} \text { ) }\end{array}$ & $\begin{array}{l}\text { Total sugar content } \\
\text { of blood } \\
\text { (mg. per } 100 \mathrm{cc} \text {.) }\end{array}$ & $\begin{array}{c}\text { Glucose } \\
\text { recovered } \\
\text { (mg. per } 100 \mathrm{cc} .)\end{array}$ \\
\hline 67 & 0 & 0 & 0 \\
\hline 67 & 50 & 117 & 50 \\
\hline 67 & 100 & 169 & 102 \\
\hline 67 & 200 & 266 & 199 \\
\hline
\end{tabular}

From Table I it will be seen that, if glucose be added to blood and the mixture deproteinised with sodium tungstate and sulphuric acid, the added glucose may be estimated quantitatively.

Tungstic acid filtrates of various bloods were prepared and the reducing powers as determined by the new technique and other methods were compared. The other methods compared included: (1) Shaffer and Hartmann [1920-21]; (2) Folin and Wu [1919]; (3) Folin [1926]; (4) Hagedorn and Jensen [1923].

Zinc filtrates were not employed for the Hagedorn and Jensen method as the original method of deproteinisation was intended for non-oxalated blood. It was decided that such figures here would be unsatisfactory since all bloods used in this work were oxalated. The results given in Tables II and III were obtained and are expressed as mg. per $100 \mathrm{cc}$. blood.

From the results obtained in the previous paper it was to be expected that the new technique would give lower results than the other methods, but this does not appear to be always the case. In every case the Hagedorn and Jensen method gave a higher result and the Folin method a lower result than by the new technique. Compared with the Shaffer and Hartmann and Folin and $\mathrm{Wu}$ methods, the new technique at times gave higher results and sometimes lower results. 


\begin{tabular}{|c|c|c|c|}
\hline \multicolumn{4}{|c|}{$\begin{array}{l}\text { e II. } \\
\text { per } 100 \text { cc.). }\end{array}$} \\
\hline & New technique & $\begin{array}{l}\text { Shaffer and Hartmann } \\
\text { method }\end{array}$ & $\begin{array}{c}\text { Folin and Wu } \\
\text { mothod }\end{array}$ \\
\hline 1 & 105 & 108 & 99 \\
\hline 2 & 103 & 95 & 91 \\
\hline 3 & 102 & 90 & 89 \\
\hline 4 & 112 & 108 & 100 \\
\hline 5 & 74 & 70 & 67 \\
\hline 6 & 86 & 95 & 95 \\
\hline 7 & 102 & 96 & 105 \\
\hline 8 & 100 & 126 & 89 \\
\hline 9 & 87 & 90 & 89 \\
\hline 10 & 86 & 74 & 89 \\
\hline 11 & 108 & 104 & 115 \\
\hline 12 & 83 & 75 & 87 \\
\hline
\end{tabular}

Table III.

Glucose (mg. per 100 cc.).

$\begin{array}{ccc}\text { New technique } & \begin{array}{c}\text { Folin } \\ \text { method }\end{array} & \begin{array}{c}\text { Hagedorn and Jensen } \\ \text { method }\end{array} \\ 99 & 84 & 127 \\ 109 & 91 & 149 \\ 86 & 70 & 131 \\ 93 & 83 & 128 \\ 108 & 88 & 144 \\ 86 & - & 115 \\ 90 & - & 123\end{array}$

An excellent criterion of the amount of non-sugar substances that are being included in a blood-sugar estimation is to determine the reducing power of blood after fermentation by yeast or glycolysis. Macleod [1926] has raised serious objections to the yeast fermentation procedure in that yeast itself contains or produces during fermentation substances which reduce and that yeast may convert the non-sugar reducing substances into non-reducing forms.

It was decided to determine the residual reduction by allowing bloods to glycolyse at $37^{\circ}$ for 24 hours with constant shaking according to the technique of Hiller, Linder and Van Slyke [1925]. At the end of 24 hours the bloods were deproteinised with sodium tungstate and sulphuric acid and the reducing values determined by the new technique. The residual reduction was found to be very low, of the order 0-6 mg. per $100 \mathrm{cc}$. blood. The residual reduction of blood as determined by the other methods is much higher, for the Folin and $\mathrm{Wu}$ method it is of the order 20-30 mg. per $100 \mathrm{cc}$.

Tungstic acid filtrates of blood were prepared and their reducing values determined by the new technique and by the Shaffer and Hartmann method. The remainder of the filtrates, after these determinations, was saturated with benzoic acid as preservative and allowed to stand at room temperature for a few days after which these determinations were repeated. The results given in Table IV were obtained.

It will be seen that these filtrates on standing show no appreciable change as determined by the new technique, but by the Shaffer and Hartmann method they show a marked increase. This phenomenon will be discussed later. 


\begin{tabular}{|c|c|c|c|}
\hline \multicolumn{4}{|c|}{ Table IV. } \\
\hline & & New technique & $\begin{array}{l}\text { Shaffer-Hartmann } \\
\text { method }\end{array}$ \\
\hline 20 & 24 hours after & $\begin{array}{l}94 \\
93\end{array}$ & $\begin{array}{r}90 \\
103\end{array}$ \\
\hline 21 & 24 hours after & $\begin{array}{l}67 \\
67\end{array}$ & $\begin{array}{l}50 \\
78\end{array}$ \\
\hline 22 & 48 hours after & $\begin{array}{l}105 \\
107\end{array}$ & $\begin{array}{l}108 \\
122\end{array}$ \\
\hline 23 & 48 hours after & $\begin{array}{l}\mathbf{7 4} \\
\mathbf{7 4}\end{array}$ & $\begin{array}{l}70 \\
84\end{array}$ \\
\hline 24 & 72 hours after & $\begin{array}{l}103 \\
105\end{array}$ & $\begin{array}{r}95^{\circ} \\
108\end{array}$ \\
\hline 25 & 72 hours after & $\begin{array}{l}112 \\
115\end{array}$ & $\begin{array}{l}108 \\
122\end{array}$ \\
\hline
\end{tabular}

Determination of the sugar content of mercury filtrates of blood by the new technique.

Bierry and Moquet [1924] and Harned [1925] employed a solution of mercuric nitrate in dilute nitric acid but the filtrates they obtained contained high concentrations of sodium nitrate. West, Scharles and Petersen [1929] besides using this reagent employed a solution of mercuric sulphate in dilute sulphuric acid. By subsequent treatment with solid barium carbonate and metallic zinc they were able to obtain filtrates with no higher concentrations of inorganic salts than tungstic acid filtrates. A modification of this latter technique was employed to prepare filtrates for sugar determination. The method was as follows.

1 vol. of blood was laked with 10 vols. of distilled water in a flask and 1 vol. of $30 \%$ mercuric sulphate in $10 \%$ sulphuric acid added. The flask was stoppered and well shaken. Solid barium carbonate was then added with shaking until the reaction of the mixture was neutral to phenolphthalein. It was filtered and to the filtrate 2-3 drops of $25 \%$ sulphuric acid were added. The filtrate was then treated with copper foil and again filtered. This filtrate, representing a 1 in 12 dilution of blood, is free from mercury and barium salts.

Solutions of pure glucose were subjected to the above treatment and it was found that their reducing values were unaffected.

Further, known quantities of pure glucose were added to samples of blood, the blood was deproteinised according to the above procedure and the reducing values of the filtrates were determined. The blood used in this experiment had been allowed to glycolyse. The results are given in Table V (mg. per $100 \mathrm{cc}$.).

$\begin{array}{ccccc} & \text { Table V. } & & \\ \text { Sugar content } & \begin{array}{c}\text { Glucose } \\ \text { of blood }\end{array} & \text { Total sugar content } & \begin{array}{c}\text { Glucose } \\ \text { of blood }\end{array} \\ 1 & 0 & 46 & 47 & 47 \\ 2 & 0 & 92 & 91 & 92 \\ 3 & 0 & 184 & 182 & 182\end{array}$


It will be seen that glucose added to blood and subjected to this treatment may be determined quantitatively.

In Table VI are given comparisons of results obtained using tungstic acid filtrates and mercury filtrates of the same bloods. The results are expressed in $\mathrm{mg}$. per $100 \mathrm{cc}$.

Table VI.

\begin{tabular}{|c|c|c|}
\hline & Tungstic acid filtrates & Mercury filtrates \\
\hline 26 & 90 & 62 \\
\hline 27 & 88 & 60 \\
\hline 28 & 90 & 49 \\
\hline 29 & 100 & 62 \\
\hline 30 & 141 & 125 \\
\hline 31 & 71 & 44 \\
\hline 32 & 85 & 64 \\
\hline 33 & 84 & 51 \\
\hline 34 & 79 & 46 \\
\hline 35 & 74 & 51 \\
\hline 36 & 83 & 55 \\
\hline 37 & 91 & 73 \\
\hline Average & $89 \cdot 8$ & $61 \cdot 8$ \\
\hline
\end{tabular}

It will be seen that the reducing values of the mercury filtrates are much lower than those of the tungstic acid filtrates. The residual reductions of bloods after glycolysis and deproteinisation by this procedure were of the order 0-6 mg. per 100 cc. It may be noted that a similar figure was obtained when tungstic acid precipitation was employed. The mercury filtrates were practically free from nitrogen, approximately $6 \mathrm{mg}$. of nitrogen per $100 \mathrm{cc}$. blood being unprecipitated.

Treatment of tungstic acid filtrates of blood with mercuric sulphate.

West, Scharles and Petersen [1929] have shown that when tungstic acid filtrates are treated with mercuric sulphate and barium carbonate the reducing values of the filtrates are lowered. They state that this decrease is due to the removal of non-sugar reducing substances.

The present writer decided to repeat this. The method of procedure was as follows.

To 20-25 cc. of tungstic acid filtrate were added 1-2 drops $50 \%$ sulphuric acid and about $0.5 \mathrm{~g}$. solid mercuric sulphate. The whole was well shaken and then about $10 \mathrm{~g}$. solid barium carbonate were added. After shaking, the mixture was filtered. To the filtrate 1 drop of $25 \%$ sulphuric acid was added and then it was treated with copper foil. It was then filtered-a solution being thereby obtained free from barium and mercury salts.

The reducing values of tungstic acid filtrates were compared before and after treatment with mercuric sulphate and then portions of the untreated tungstic acid filtrates were saturated with benzoic acid (as preservative), allowed to stand at room temperature for several days and the comparisons repeated. The results, expressed as mg. per $100 \mathrm{cc}$. blood, are presented in Table VII. 


\begin{tabular}{|c|c|c|c|}
\hline \multicolumn{4}{|c|}{ Table VII. } \\
\hline Exp. & & $\begin{array}{l}\text { Tungstic acid filtrates } \\
\text { before treatment } \\
\text { with } \mathrm{HgSO}_{4}\end{array}$ & $\begin{array}{l}\text { Tungstic acid filtrates } \\
\text { after treatment } \\
\text { with } \mathrm{HgSO}_{4}\end{array}$ \\
\hline 38 & 3 days afterwards & $\begin{array}{l}149 \\
150\end{array}$ & $\begin{array}{l}121 \\
148\end{array}$ \\
\hline 39 & 5 days afterwards & $\begin{array}{l}91 \\
91\end{array}$ & $\begin{array}{l}75 \\
89\end{array}$ \\
\hline 40 & 4 days afterwards & $\begin{array}{l}88 \\
88\end{array}$ & $\begin{array}{l}64 \\
88\end{array}$ \\
\hline 41 & 4 days afterwards & $\begin{array}{l}76 \\
76\end{array}$ & $\begin{array}{l}55 \\
74\end{array}$ \\
\hline 42 & 5 days afterwards & $\begin{array}{l}221 \\
221\end{array}$ & $\begin{array}{l}194 \\
222\end{array}$ \\
\hline 43 & 5 days afterwards & $\begin{array}{l}100 \\
100\end{array}$ & $\begin{array}{r}85 \\
101\end{array}$ \\
\hline 44 & 7 days afterwards & $\begin{array}{r}83 \\
82\end{array}$ & $\begin{array}{l}66 \\
80\end{array}$ \\
\hline 45 & 5 days afterwards & $\begin{array}{l}160 \\
160\end{array}$ & $\begin{array}{l}155 \\
162\end{array}$ \\
\hline 46 & 6 days afterwards & $\begin{array}{l}85 \\
85\end{array}$ & $\begin{array}{l}70 \\
85\end{array}$ \\
\hline 47 & 6 days afterwards & $\begin{array}{l}100 \\
102\end{array}$ & $\begin{array}{r}82 \\
101\end{array}$ \\
\hline 48 & 4 days afterwards & $\begin{array}{l}91 \\
91\end{array}$ & $\begin{array}{l}74 \\
91\end{array}$ \\
\hline 49 & 4 days afterwards & $\begin{array}{l}115 \\
116\end{array}$ & $\begin{array}{r}93 \\
114\end{array}$ \\
\hline
\end{tabular}

\section{Discussion.}

The reducing values of blood deproteinised with the mercuric sulphate reagent are much lower than when deproteinised with sodium. tungstate and sulphuric acid. The reducing values of tungstic acid filtrates are lowered by treatment with mercuric sulphate when the treatment is carried out immediately after deproteinisation, but, when these same filtrates are allowed to stand at room temperature for several days, treatment with mercuric sulphate has no effect upon their reducing values. The reducing values of tungstic acid filtrates are unaffected by standing at room temperature when saturated with benzoic acid.

Since the reducing values of tungstic acid filtrates and mercury filtrates of glycolysed bloods are not capable of estimation, these differences observed with fresh tungstic acid filtrates and bloods cannot be due to the non-sugar fraction of the blood as stated by West, Scharles and Petersen [1929].

Martland, Hansman and Robison [1924] state that if laked blood is incubated at $37^{\circ}$ the reducing value increases as determined by the Hagedorn and Jensen method. They attribute this to the presence of a hexosephosphoric acid which they state is present in blood in appreciable amounts. Grevenstuk [1929] states that zinc hydroxide as used in the above method precipitates degradation products of proteins incompletely. Martland, Hansman and 
Robison found that the inorganic phosphorus also increased but at a much greater rate than the reducing value.

From the experimental evidence in this paper it seems that a part of the sugar in tungstic acid filtrates is in combination with one or more substances in the filtrates, this or these substances being precipitated during the mercuric sulphate treatment, the combined sugar being precipitated as well. On standing a slow hydrolysis takes place, setting free this "bound" sugar so that at this stage it would not be precipitated by the mercuric sulphate treatment.

It has been shown by glycolysis experiments that only sugar has been determined in tungstic acid filtrates by the technique described in the preceding paper. This "bound" sugar is also estimated completely by this technique since the reducing values of tungstic acid filtrates are unaltered by standing. The lower values obtained by the Folin and Wu [1919], Folin [1926] and Shaffer-Hartmann [1920-21] methods are probably due to the fact that this "bound" sugar is being incompletely determined. The increase of the reducing values of tungstic acid filtrates on standing, as determined by the Shaffer-Hartmann method, is due to the hydrolysis of the "bound" sugar.

The low reducing values of iron and zinc filtrates in the MacLean [1916] and Hagedorn and Jensen [1923] methods respectively are no doubt due to the fact that, in the course of the precipitations, the "bound " sugar is removed.

It will be noticed that bloods deproteinised with mercuric sulphate directly give much lower results for free sugar than do tungstic acid filtrates similarly treated. This is probably due to a partial hydrolysis of the "bound" sugar taking place during the initial tungstic acid precipitation and subsequent filtration.

The unknown sugar combination appears to be very loose and to break down easily.

\section{SUMmary.}

1. By the new technique recommended in the preceding paper the sugar content of tungstic acid filtrates is determined completely. Non-sugar substances present in the filtrates do not appreciably affect the results.

2. The sugar content of tungstic acid filtrates as determined by the Folin and $\mathrm{Wu}$ [1919], Folin [1926] and Shaffer-Hartmann [1920-21] methods are low.

3. Part of the sugar in a tungstic acid filtrate is in combination with other substances in the filtrate. In this form it is precipitated by treatment of the filtrate with mercuric sulphate and barium carbonate.

4. On allowing a tungstic acid filtrate to stand, however, a hydrolysis appears to take place, so that the "bound" sugar becomes free.

In conclusion I desire to thank Professor E. P. Cathcart and Dr D. P. Cuthbertson for their very helpful criticism and advice. I also wish to express my thanks to the Medical and Surgical Staffs of the Royal Infirmary, Glasgow, for their active co-operation in supplying me with samples of blood. 


\section{REFERENCES.}

Bailey and Myers (1916). J. Biol. Chem. 24, 147.

Bang (1918). Biochem. Z. 87, 248, 264.

Benedict (1927). J. Biol. Chem. 76, 457.

Bierry and Moquet (1924). Compt. Rend. Soc. Biol. 40, 1316.

De Wesselow (1919). Biochem. J. 13, 148.

Everett (1929). J. Biol. Chem. 82, 369.

Folin (1926). J. Biol. Chem. 67, 357.

— and Wu (1919). J. Biol. Chem. 38, 91.

Grevenstuk (1929). Ergebn. Physiol. 28, 1.

Hagedorn and Jensen (1918). Ugester. Laeg. 80, 1217.

- (1923). Biochem. Z. 135, 46.

Harned (1925). J. Biol. Chem. 65, 555.

Herbert and Groen (1929). Biochem. J. 23, 339.

Hiller, Linder and Van Slyke (1925). J. Biol. Chem. 64, 625.

Höst and Hatlehol (1920). J. Biol. Chem. 42, 347.

Lewis and Benedict (1915). J. Biol. Chem. 20, 61.

MacLean (1916). J. Physiol. 50, 168.

Macleod (1926). Carbohydrate metabolism and insulin. (London, Longmans.)

Martland, Hansman and Robison (1924). Biochem. J. 18, 1152.

Shaffer and Hartmann (1920-21). J. Biol. Chem. 45, 365.

Somogyi (1929). Proc. Soc. Exp. Biol. Med. 26, 353.

- (1930). J. Biol. Chem. 86, 655.

Stepp (1921). Arch. exp. Path. Pharm. 90, 105.

West, Scharles and Petersen (1929). J. Biol. Chem. 82, 137. 